DOI: https://doi.org/10.24867/12BE45Gavrilovic

\title{
DODELA RADNIH ZADATAKA U POSLOVNOM PROCESU UPOTREBOM PHARO PROGRAMSKOG JEZIKA
}

\section{ASSIGNMENT OF WORK TASKS IN THE BUSINESS PROCESS USING THE PHARO PROGRAMMING LANGUAGE}

\author{
Nemanja Gavrilović, Fakultet tehničkih nauka, Novi Sad
}

\begin{abstract}
Oblast - RAČUNARSTVO I AUTOMATIKA
Kratak sadržaj - u radu su opisani poslovni procesi, alati koji se koriste za njihovo modelovanje i programski jezici Smalltalk i Pharo. Prikazani su šabloni za dodelu zadataka učesnicima u procesu. Predstavljena je implementacija, uz prikaz klasa i njihovih metoda kojima se dolazi do željenog rešenja.
\end{abstract}

Ključne reči: Poslovni procesi, šabloni za dodelu zadataka, Pharo programski jezik

Abstract - The thesis describes the business processes, the tools used for their modeling and the programming languages Smalltalk and Pharo. Templates for assigning tasks to participants in the process are shown. The implementation is presented, with a presentation of classes and their methods by which the desired solution is reached.

Keywords: process engine, assigning templates, Pharo

\section{UVOD}

Poslovni proces sastoji se od skupa aktivnosti koje se koordinisano izvršavaju u odgovarajućem organizacionom i tehnološkom okruženju. Ove aktivnosti zajedno dovode do poslovnog cilja. Svaki poslovni proces izvršava jedna organizacija, ali on može imati interakcije sa poslovnim procesima drugih organizacija [1]. Učesnici u poslovanju organizacije obavljaju određene zadatke. Ti zadaci mogu im biti dodeljeni na različite načine. Zadatak ovog rada je kreiranje proširenja za NewWave softver, koje će omogućiti rad sa korisnicima i njihvoim grupama, kako bi se omogućila dodela zadataka.

Rešenje je potrebno implementirati u Pharo programskom jeziku.

\section{POSLOVNI PROCESI}

Poslovni proces može se definisati i kao niz aktivnosti koje pokreće određeni događaj (ili više njih), a čiji je zadatak ostvarivanje zajedničkog cilja. Proces koristi resurse prilikom ostvarivanja definisanog cilja, podložan je spoljašnjim uticajima i njime treba upravljati.

Kako se obim proizvodnje povećavao i usložnjavao i tehnologija napredovala, tako su procesi postali veći i zahtevniji. Današnji, moderni procesi, imaju svoj životni ciklus.

\section{NAPOMENA:}

Ovaj rad proistekao je iz master rada čiji je mentor bio dr Miroslav Zarić, vanr. prof.
Prvu fazu čine dizajn i analiza. Druga faza jeste konfigurisanje, u kojoj se odlučuje da li će poslovni proces koristiti informacioni sistem ili ne. Sledeća faza je izvršavanje, u kojoj se pokreću instance procesa da bi se ostvarili željeni rezultati organizacije. I na kraju, peta faza je evaluacija, u kojoj se analiziraju podaci prikupljeni u prethodnim fazama.

Osnovni cilj svakog poslovnog procesa je da stvori vrednost za korisnika. Cilj organizacije ne mora se isključivo izvršavati kroz jedan poslovni proces. Cilj se može izvršiti i kroz više procesa koji su u međusobnoj interakciji sa drugim procesima ili procesima iz drugih organizacija. Oni zajedno treba da na efektivan način doprinose stvaranju vrednosti za korisnika.

Prvu fazu čine dizajn i analiza. Druga faza jeste konfigurisanje, u kojoj se odlučuje da li će poslovni proces koristiti informacioni sistem ili ne. Sledeća faza je izvršavanje, u kojoj se pokreću instance procesa da bi se ostvarili željeni rezultati organizacije. I na kraju, peta faza je evaluacija, u kojoj se analiziraju podaci prikupljeni $\mathrm{u}$ prethodnim fazama.

Osnovni cilj svakog poslovnog procesa jeste da stvori vrednost za korisnika. Cilj organizacije ne mora se isključivo izvršavati kroz jedan poslovni proces. Cilj se može izvršiti i kroz više procesa koji su u međusobnoj interakciji sa drugim procesima ili procesima iz drugih organizacija. Oni zajedno treba da na efektivan način doprinose stvaranju vrednosti za korisnika.

\section{BUSINESS PROCCES MODELING AND NOTATION(BPMN)}

BPMN je standard za modelovanje poslovnih procesa koji definiše grafičke notacije za specificiranje poslovnih procesa.

Nastao je kao proizvod Business Process Management Initiative (BPMI). Grafičkim notacijama standardizuju se elementi procesa, čime se postiže nezavisnost od platforme na kojoj će se proces izvršavati.

Elementi koji čine BPMN dijagrame mogu se podeliti u 4 grupe:

1. Objekti toka (flow objects) : događaji, aktivnosti, grananja

2. Objekti povezivanja (connecting objects): asocijacije, tokovi poruka (Messages Flow), tokovi procesa (Sequence Flow)

3. Swimlanes: pools ili lane

4. Artifacts: grupe, anotacije, objekti podataka 


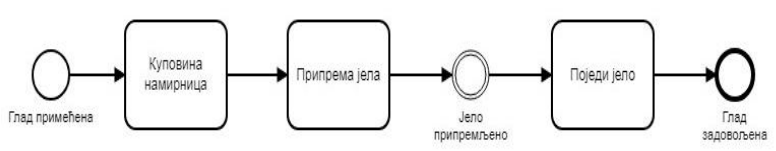

Slika 1: Proces pripreme jela [2]

Događaji se označavaju krugovima koji sadrže simbole u sebi u zavisnosti od tipa događaja. Događaj predstavlja nešto što se desilo u toku procesa. Aktivnosti koristimo kada je potrebno neku radnju obaviti nad podacima $u$ procesu.

Korisnički zadaci (User Tasks) su najčešće korišćeni tip. U ovom tipu aktivnosti ljudi vrše direktan uticaj nad podacima koji se nalaze u poslovnom procesu. Veza između organizacione strukture i poslovnog procesa ostvaruje se dodelom radnih zadataka.

Radni zadaci predstavljaju instance aktivnosti koje su dodeljene određenim zaposlenim na obavljanje [1]. Da bi tok procesa postojao, potrebno je povezati aktivnosti i događaje i utvrditi uslove kojima se određuje tok kretanja. U BPMN-u povezivanje se ostvaruje upotrebom odgovarajućih grananja i spajanja.

U zavisnosti od potreba modela, kretanja nakon donošenja odluke mogu biti paralelne, bira se samo jedna putanja, obe, sve ili neke od.

\section{XML PROCESS DEFINITION LANGUAGE (XPDL)}

XPDL je opisan u ovom poglavlju kao jedan od najčešće korišćenih jezika za modelovanje i definisanje poslovnih procesa u kompanijama. Dati su osnovne informacije o njegovom nastanku i prikazani su elementi koji se koriste prilikom kreiranja.

\subsection{Osnovne informacije i elementi}

XPDL [3] je jezik baziran na XML-u, koji služi za opis definicije procesa, kreiranog od Workflow Management Coalition (WfMC) [4]. WfMC je osnovana u maju 1993. godine.

Workflow Reference Model (WRM) objavljen je 1995. godine i još uvek se koristi kao osnova za mnoge poslovne procese $\mathrm{i}$ sisteme koji su danas u upotrebi. WRM se sastoji od pet interfejsa koji ovaj model čine generičkim i daju mu mogućnost da odgovori različitim zahtevima u procesu poslovanja.

Osnovni cilj XPDL-a jeste da sačuva i razmenjuje dijagram procesa, tj. omogućava jednom alatu da modeluje proces, drugom da ga čita i modifikuje i na kraju, nekom alatu da izvršava proces.

Uz pomoć XPDL-a mogu se definisati specifični delovi poslovnog procesa. Specifikacija XPDL-a koristi kao mehanizam za razmenu definicija procesa. XPDL formira standard za razmenu koji omogućava proizvodima da podržavaju različite interne prikaze definicija procesa sa funkcijom uvoza/izvoza.

Glavni elementi XPDL koji se mapiraju na elemente BPMN su: Package (Paket), Application (Aplikacija), Workflow-Process (Proces), Activity (Aktivnost),
Transition (Tranzicija), Participant (Učesnik), DataField (Polje podatka) i DataType (Tip podatka).

\section{DODELA KORISNIČKIH ZADATAKA}

Dodela korisničkih zadataka je jedan od ključnih aspekata za uspešno izvršavanje procesa u organizacionim strukturama kompanija. Prikazano je kako BPMN izvršno okruženje upravlja zadacima i kako korisnički zadaci utiču na njegov rad i izvršavanje procesa.

\section{1 Šabloni za dodelu zadataka}

Svaki korisnički zadatak u procesu poslovanja ima svoj životni ciklus. Ovaj tip zadatka može prelaziti iz stanja u stanje, sve dok se ne proglasi da je završen. Da bi proces uspešno nastavio da funkcioniše i teži ka cilju zbog kojeg je modelovan, neophodno je proglasiti odgovornog za izvršavanje korisničkog zadataka. Ukoliko se izvršilac ne navede proces će ostati zaglavljen i neće ići dalje od trenutnog stanja. Kada je zadatak kreiran inicijalno mu je dodeljen korisnik ili grupa korisnika, u zavisnosti od konfiguracije procesa. Zadatak može biti dodeljen jednom korisniku, listi korisnika ili listi grupa. Svaki zadatak, da bi uspešno bio obavljen, mora se razrešiti do korisnika. To znači da ga neko mora preuzeti na sebe, ne može se ostati na nivou grupe.

U procesu modelovanja poslovnog sistema, pored definisanja toka procesa i određivanja aktivnosti koje su neophodne da bi se postigao cilj, potrebno je i odrediti koja aktivnost kom delu organizacione strukture pripada. Uočavamo nekoliko šablona koji nam to omogućavaju.

Kada je prilikom modelovanja određeno da se sve instance neke aktivnosti dodele tačno jednoj osobi radi se o direktnoj dodeli. Zadaci se mogu dodeljivati na osnovu uloge korisnika, prethodne istorije. Odluka ko je izvršilac ne mora se dodati u procesu modelovanja, već se može to uraditi i prilikom izvršavanja procesa.

Razdvajanjem nadležnosti se zasniva na tome da više izvršilaca odradi isti posao, uz ograničenje da jedan izvršilac isti posao ne može obaviti više od jednom. Autorizacijom omogućavamo dodelu na osnovu pozicije u organizacionoj strukturi. Šablon obrade predmeta (case handling) koristimo kada je potrebno da izvršilac bude upoznat sa slučajem.

\section{OSNOVE PROGRAMSKOG JEZIKA SMALLTALK I PHARO}

U ovom poglavlju opisan je programski jezik Smalltalk na kojem se bazira Pharo u kojem je izvršena implementacija dodele zadataka u poslovnom procesu.

\subsection{Programski jezik Smalltalk}

Smalltalk je nastao ranih sedamdesetih godina prošlog veka u Xerox-ovom centru za istraživanje Palo Alto Research Center (PARC). Prva verzija pojavila se u javnosti 1980. godine, ali nije bila dostupna svima već samo izabranim kompanijama, da bi 1983. nakon izlaska druge verzije postala javno dostupna.

Smalltalk je objektno-orijentisan, dinamčki programski jezik [5]. S obzirom da je sve objekat, u Smalltalk-u ne postoje tipovi, pa se tako novi objekat može kreirati kao 
nova instanca klase. Primitivni tipovi kao što su int, boolean ili character su takođe objekti, odnosno instance odgovarajućih klasa i operacije nad njima se vrše slanjem poruka. Klase su objekti koji su instance njihovih meta klasa. Objekti komuniciraju slanjem poruka drugim objektima. Bilo koja poruka može biti poslata bilo kojem objektu.

\section{2 . Programski jezik Pharo}

Pharo su stvorili S.Ducasse i M.Denker u martu 2008. godine [6], fokusirajući se na moderno softversko inženjerstvo i razvojne tehnike i tehnologije. Prva verzija Pharo programskog jezika pojavila se u aprilu 2010. godine i nalazi se pod licencom MIT-a. Uspešno se koristiti na svim operativnim sistemima, MAC, Linux, Android, iOS i Windows. Kao što je rečeno komunikacija između objekata obavlja se preko poruka. Postoje tri tipa poruka: unarne, binarne i poruke ključnih reči (keyword). Unarne se izvršavaju prve, zatim binarne i na kraju keyword. Poruke koje imaju isti prioritet izvršavaju se s' leva na desno, osim ukoliko se ne koriste zagrade, koje menjaju tok izvršavanja.

\section{7 . IMPLEMENTACIJA REŠENJA}

Kao što je već rečeno, tema ovog rada je dodeljivanje korisničkih zadataka prilikom modelovanja poslovnog procesa. Za potrebe implementacije korišćen je Pharo programski jezika u razvojnom okruženju Pharo Virtual Machine.

Glavni zadatak je bio napraviti proširenje (plug-in) za NewWave Process Engine [7], kojim će se omogućiti učitavanje predefinisanih korisnika i grupa i omogućiti njihovo dodavanje korisničkim zadacima. NewWave se razvija na Fakultetu tehničkih nauka u Novom Sadu na Katedri za informatiku. NewWaveUserManagment je proširenje koje je kreirano za potrebe ovog rada. Na slici 2 predstavljen je dijagram klasa korišćenih prilikom implementacije.

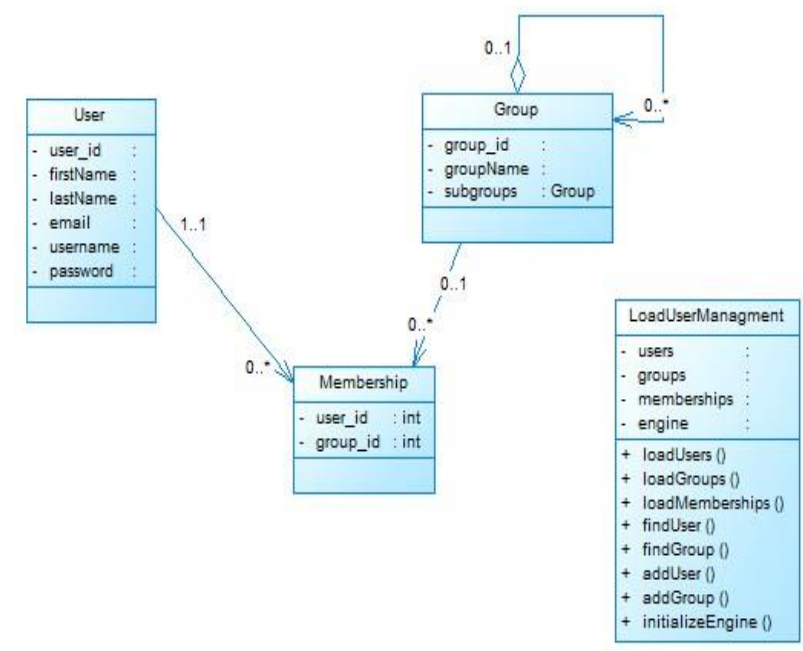

Slika 2: Dijagram klasa modula za upravljanje korisnicima i grupama

Klase User i Group predstavljaju entitete koji se dodeljuju određenim zadacima. Klasa User je modelovana sa standardnim poljima kojima se opisuju korisnici: firstName, lastName, email, username, password. Klasa Group sadrži naziv i može sadržati podgrupe koje su takođe instance klase Group. Prilikom dodeljivanja korisnika ili grupe konkretnom zadatku se prosleđuje identifikacioni broj korisnika/grupe. Veza između ova dva entiteta ostvarena je uz pomoć klase Membership, radi lakše kontrole i upravljanja nad učesnicima u procesu.

Svaki korisnik može, a i ne mora imati grupu. Takođe, može imati više od jedne. U grupi se može naći više od jednog korisnika. Klasa u čijoj je nadležnosti rad sa ovim entitetima je LoadUserManagment.

LoadUserManagment je klasa u kojoj se nalaze svi trenutni korisnici, grupe i veze između njih. Takođe, ima referencu prema engine-u. Metode koje omogućavaju učitavanje korisnika, grupa i članstava su respektivno loadUsers, loadGroups i loadMemberships, sa parametrom koji predstavlja putanju do fajla. Podaci u fajlovima se nalazi u JSON formatu. Da bi se tako struktuirani podaci mapirali na klase u Pharo-u korišćena je NeoJSON biblioteka [8].

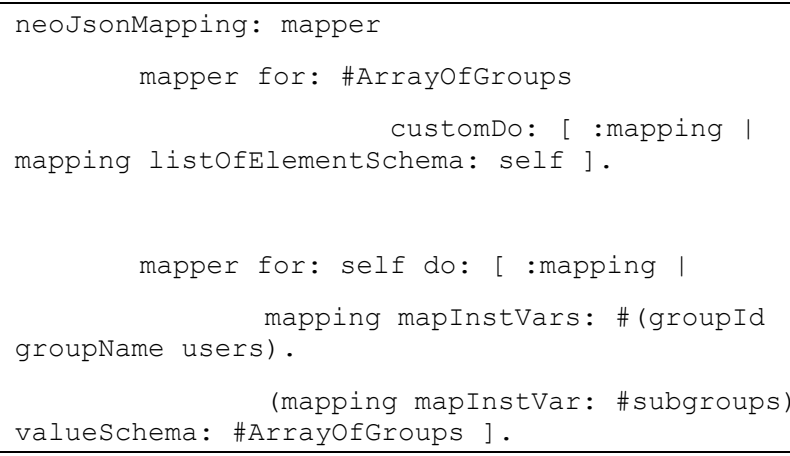

Listing 1: Mapiranje entiteta Group na JSON za učitavanje

Ovako učitani podaci nalaze se u kolekcijama objekata $\mathrm{u}$ klasi LoadUserManagment i to redom, users, groups $\mathrm{i}$ memberships. Ova klasa omogućava i dodavanje entiteta prilikom definisanja samih zadataka prilikom modelovanja. Dodavanje u kolekcije moguće je pomoću metoda addUser, addGropu, addMembership gde su parametri objekti klasa koji se dodaju.

\section{ZAKLJUČAK}

U radu su prikazani koncepti poslovnih procesa, objašnjene su faze životnog ciklusa procesa i prikazan je proces njegovog modelovanja, kao i načini komunikacije unutar samog procesa, ali i eksterne veze između više procesa. Predstavljen je BPMN koji se koristi za modelovanje poslovnog procesa. Pored BPMN-a, u ovoj delatnosti, najviše se koristi XPDL, zbog svog formata koji je nezavisan od platforme. Dat je pregled osnovnih informacija o XPDL i njegovih elemenata. Obrađeni su šabloni na osnovu kojih se dodeljuju izvršioci zadataka.

Kao glavni zadatak ovog rada bilo je kreiranje proširenja NewWave softvera, kojim će se omogućiti podrška za korisnike i grupe korisnika koji učestvuju u procesu. Implementacija rešenja izvršena je u programskom jeziku Pharo, koji je nastao iz Smalltalk-a. Trenutno u NewWave-u moguća je samo direktna dodela korisnika ili njihovih korisničkom zadatku, pa bi ovo rešenje trebalo 
proširiti sa još nekim šablonom za dodeljivanje izvršioca zadatka.

\section{LITERATURA}

[1] Miroslav Zarić, predavanja iz predmeta „Upravljanje poslovnim procesima“, Katedra za informatiku, FTN, Novi Sad, 2019. godine

[2] https://camunda.com (pristupljeno u avgustu 2020.)

[3] http://xpdl.org/ (pristupljeno u septembru 2020.)

[4] "Workflow Management Coalition Workflow

Standard: Workflow Process Definition Interface - XML

Process Definition Language (XPDL) (WFMCTC-1025).

"Technical report, Workflow Management Coalition,

Lighthouse Point, Florida, USA, 2002.

[5] Adele Goldber, ,Smalltalk-80: The Interactive Programming Environment"

[6] Black, A., Ducasse, S., Nierstrasz, O., Pollet, D., Cassou, D., Denker, M., „Pharo by example. 2009.“

[7] https://github.com/skaplar/NewWave

[8] https://ci.inria.fr/pharo-

contribution/job/EnterprisePharoBook/lastSuccessfulBuil d/artifact/book-result/NeoJSON/NeoJSON.html

(pristupljeno u septembru 2020.)

\section{Kratka biografija:}

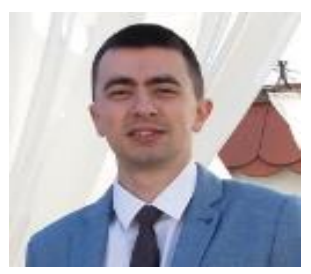

Nemanja Gavrilović rođen je 14. avgusta 1995. godine u Šapcu, Srbija. Srednju školu završio je 2014. godine u Malom Zvorniku, smer ekonomski tehničar. Iste godine upisuje Fakultet tehničkih nauka u Novom Sadu, odsek Računarstvo i automatika. Na trećoj godini osnovnih akademskih studija opredelio se za usmerenje Primenjene računarske nauka i informatika. Nakon osnovnih studija upisuje master studije na istom odseku i smeru, usmerenje Elektronsko poslovanje. 